\title{
Global operational data services for storm surge and fluvial flood forecasting
}

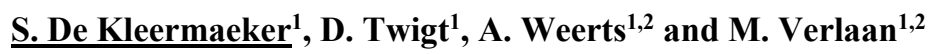 \\ ${ }^{1}$ Deltares, Delft The Netherlands \\ ${ }^{2}$ Wageningen University \& Research, The Netherlands \\ ${ }^{3}$ TUDelft, The Netherlands \\ Email: Simone.DeKleermaekerr@Deltares.nl
}

\begin{abstract}
Riverine floods and coastal inundation by storm surges are the most frequent of natural disasters, affecting millions of people across the globe every year. The forecasting of floods and storm surge at the global scale is crucial to preparing for severe events and providing early awareness where local models and warning services are lacking. Developments in modelling capabilities, data availability, and computational resources in recent years have made it possible to produce global scale flood forecasts. Operational systems currently have the capability to produce discharge and water level forecasts in the medium-range and disseminate forecasts and early warning products in real time across the globe, in support of national forecasting capabilities.
\end{abstract}

Deltares currently runs two global forecasting systems: Global Flood Forecasting Information System (GLOFFIS) and Global Storm Surge Information System (GLOSSIS). These systems are run from an open experimental information and communications technology facility, IdLab, and are being used to test new ideas around interoperability, hydrological/hydrodynamical predictability, big data, and visualization. GLOFFIS and GLOSSIS produce global flood and storm surge forecasts up to four times per day, with a 10 day forecast horizon (Deltares, 2017). These forecasts can be used for early warning in areas that currently lack adequate local forecasting capabilities. In areas where such capabilities are already available, these systems can provide boundary conditions to regional or local models to further improve these.

The underlying hydrodynamic and hydrological models are constantly improved and updated, to further increase their accuracy. With improvements in weather forecasting, future advances may include more seamless hydrological forecasting at the global scale alongside a move towards multi-model forecasts and grand ensemble techniques, responding to the need of developing multi-hazard early warning systems for disaster risk reduction.

The global forecasts from GLOFFIS and GLOSSIS are made available through various online channels, like web applications and FTP. A subset of results has been made available free of charge in June 2017 via www.GlobalFloodForecast.com. It is foreseen that the full or higher resolution results will be provided through a service with subscription fee by the end of 2017.

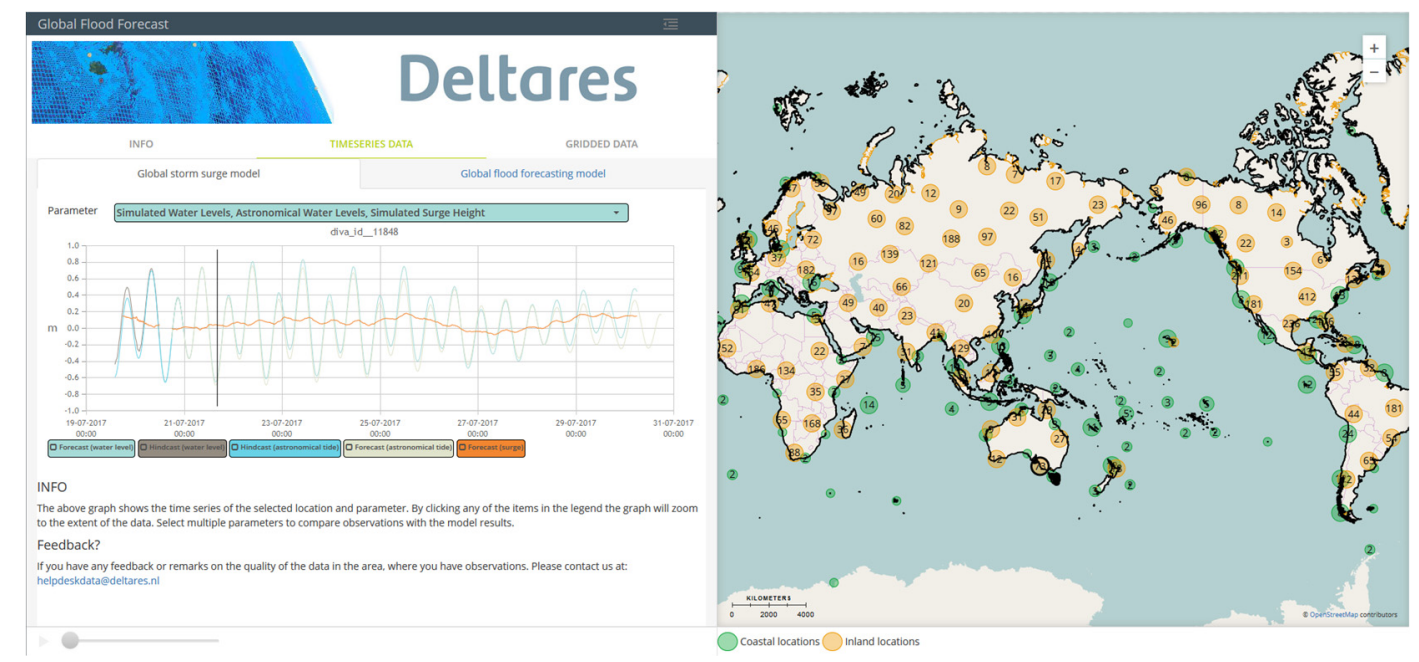

Keywords: $\quad$ Global operational forecasting system, storm surge and tide, fluvial flooding 


\section{INTRODUCTION}

Floods are the most frequent of natural disasters, affecting millions of people across the globe every year. To manage flood related risks, preparedness by means of flood forecasting and early warning services is one of the principal strategies. For many at-risk areas, however, the availability of such services is still lacking. Here, flood forecasting at the global scale can provide a solution.

Flood and storm surge forecasting at the continental and global scale has only become possible in recent years (Emmerton et al., 2016; Verlaan et al., 2015) due to the availability of meteorological forecast, global scale precipitation products and global scale hydrologic and hydrodynamic models. Deltares has setup a research-oriented Global Storm Surge Information System (GLOSSIS) and multi model operational flood forecasting system (GLOFFIS) based on Delft-FEWS in an open experimental ICT facility called IdLab.

\section{OPERATIONAL GLOBAL INFORMATION SYSTEMS}

The IdLab is an interactive data research laboratory. The experimental nature of the facility allows experts to come together with other partners to test and develop new approaches and learn about new tools, methods and models in a "playground" environment. The facility has high computing power and access to a variety of datasets, models and other services.

Furthermore, the IdLab facilitates emergency advice and support before and during international and national disasters such as coastal and riverine flooding. Experts can rapidly set up models in response to decisionmakers' needs and utilize our information systems such as the global flood (GLOFFIS) and storm surge (GLOSSIS) forecast models. Both systems are based on the DELFT-FEWS platform, Werner et al. (2012). The setup allows running regional high resolution or other large scale hydrological or hydrodynamic models within the operational system/setup in parallel.

\subsection{GLOSSIS}

GLOSSIS runs the Global Storm surge and Tide Model (GTSM) four times per day using meteorological wind and pressure field forecasts from the National Centers for Environmental Prediction's Global Forecasting System (NCEP/GFS) as forcing.

The underlying hydrodynamic model of GLOSSIS is GTSM, a Global Tide and Storm Surge Model developed in Delft3D-FM (Kernkamp, 2011). Using the new flexible mesh (FM) technology, the

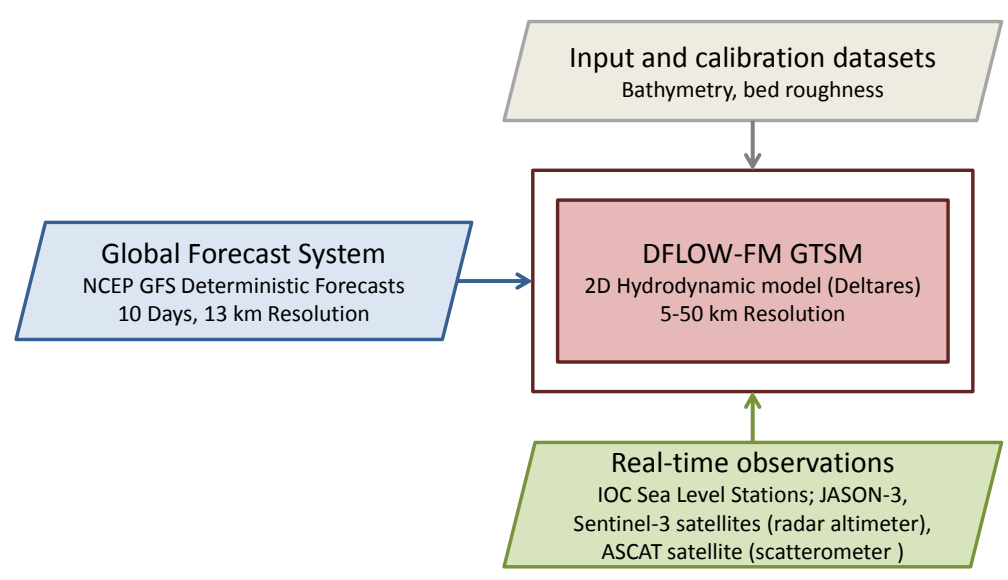

Figure 1. Components of GLOSSIS mesh resolution of the GTSM can be refined at the coast for local-scale applications without the need for consecutive nesting. GTSM has a coastal resolution of only $5 \mathrm{~km}$, not far from the resolution of many regional models.

A first implementation of the global storm surge model performed (GTSMv1) well in deep water, Muis et al (2016). Ongoing research on improvements of the model in shallow and coastal regions (GTSMv2) has led to improved results. The accuracy of GTSMv2 has much improved compared to version 1, due to a number of improvements to the modelled physics and numerical accuracy. The formulations for Self Attraction and Loading and dissipation by generation of internal tides have been improved significantly, Apecechea et al. (2017). The grid has been refined where this had most impact, at steep bathymetry. Although the grid size has increased the model can still run easily on a few nodes.

Real-time observations of the water level at 675 locations across the globe are collected from the IOC Sea Level Station Monitoring Facility every 10 minutes and are imported as they become available. Furthermore, GLOSSIS imports the real-time radar altimeter water level and surge measurements from the JASON-3 and Sentinel-3 satellites, as well as scatterometer measurements from the ASCAT satellite. All observed data is displayed alongside time series of the model results for an on-the-fly qualitative comparison with the GTSM model results. Initiatives on more elaborate forms of comparison and on assimilation of this data are in progress. This work will focus on updating of the model state using Kalman filtering techniques, Zijl et al. 
(2015). This requires a more rigorous quality control of the data, which is also in progress, Verlaan et al., 2015.

\subsection{GLOFFIS}

Similar to the approaches taken by many of the continental-scale flood forecasting systems, GLOFFIS uses several meteorological inputs to drive the hydrological component of the system. The idea behind this is to validate, verify, and inter-compare real-time rainfall (alongside temperature and potential evaporation) products as they become available.

Initial conditions are derived from historical forcing based on both the GFS and the ECMWF control forecast (extracted from the TIGGE archives [THe Observing System Research and Predictability EXperiment (THORPEX) Interactive Grand Global Ensemble]) and a combination of FEWSNET (Africa) and Climate Prediction Center (CPC) Unified Gauge-Based Analysis of Global Daily Precipitation, complimented by GFS temperature and potential evaporation.

The underlying hydrological models of GLOFFIS are the PCRaster Global Water Balance model (PCRGLOB-WB), World-Wide Water Resources Assessment model (W3RA) and WFLOW models. The W3RA and WFLOW models presently apply a resolution of $\sim 50 \mathrm{~km}$, and efforts are underway to increase the resolution to $5 \mathrm{~km}$. Both the W3RA (van Dijk et al., 2013) and PCRGLOB-WB (van Beek et al., 2009) models are run in deterministic and/or ensemble mode using GFS, GEFS and ECMWF-EPS (latency 2 days). Besides running these forecasts operationally, GLOFFIS will be used for experiments into predictability of floods (and droughts) and their dependency on initial state estimation (e.g. through data assimilation), meteorological forcing and the hydrologic models used.

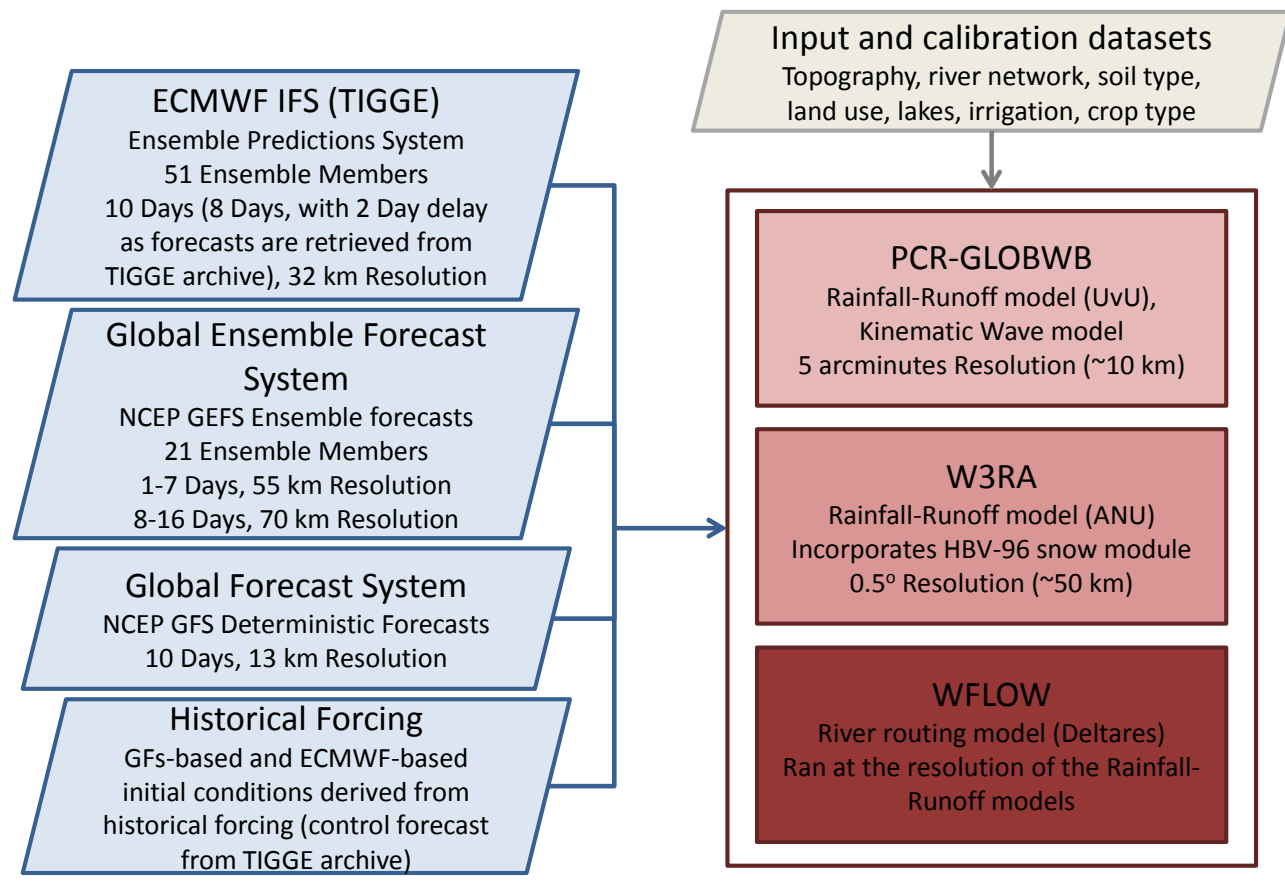

Figure 2. Components of GLOFFIS

Current global flood forecasting systems heavily rely on forecast forcing (precipitation, temperature, reference potential evaporation) to derive initial state estimates of the hydrological model for the next forecast (e.g. by gluing the first day of subsequent forecast as proxy for the historical observed forcing). It is clear that this approach is not perfect and that data assimilation can help to overcome some of the weaknesses of this approach. So far most hydrologic data assimilation studies have focused on catchment scale. In GLOFFIS we conduct a data assimilation experiment by assimilating multiple streamflow observations across the contiguous United States (CONUS) into a global hydrological model (W3RA) and run with and without localization method using OpenDA in GLOFFIS, Weerts et al (2016). Satellite based discharge measurements (Van Dijk, 2016) are derived on a daily basis for on-the-fly comparison. 
In the future, the Japan Aerospace Exploration Agency (JAXA) Global Satellite Mapping of Precipitation (GSMaP) and the Global Precipitation Measurement (GPM) Integrated Multi-satellitE Retrievals for GPM (IMERG) products will also be added as additional datasets from which to derive initial conditions.

\section{Forecast Verification}

Thorough statistical forecast verification of GLOFFIS is underway using available open discharge and meteorological forecast data alongside (real-time) eyeball verification. Real-time discharge data is being collected and can be accessed and compared with the simulated discharge within the Delft-FEWS GLOFFIS platform and reports generated by the system. The verification threshold levels are derived from long historical discharge records and historical simulations, similar to the methods used in other continental- and global-scale forecasting systems, Alfieri et al (2013).

\section{USE CASES AND EXPERIMENTS}

\subsection{GLOSSIS - operational storm surge and tide forecasting during Hurricane Matthew}

In October 2016 category 5 Hurricane Matthew affected the Caribbean Sea and the East coast of the USA. Based on the GFS meteorological forcing for hurricane Matthew, GLOSSIS produced a forecast surge level and corresponding alert levels at the DIVA output locations (Figure 3). Significant water levels were forecasted for this event (i.e. red alert level). The maximum potential inundation was derived from the forecast water level as well.

Further analysis showed that, although significant water levels were achieved during this actual event, alert levels shown in GLOSSIS are overestimated. This can be partially contributed to the ERA interim wind data used in the re-analysis by Muis et al. (2016), which underestimates cyclones. As a result, the return period levels and subsequent alert levels based on this re-analysis were underestimatied. To improve this, the re-analysis will be repeated for with the upcoming new ERA Interim dataset, which has a higher resolution and resolves the high wind speeds achieved in hurricane events better.

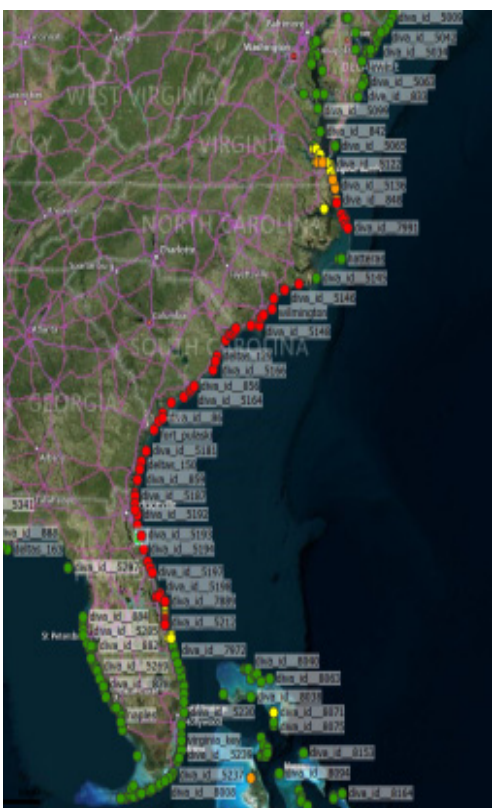

Figure 3. Forecast of alert levels for storm surge due to Hurricane Matthew

\subsection{GLOSSIS - operational boundary conditions for Mozambique}

Tropical cyclones originating in the tropical latitudes of the Indian Ocean occur about once a year across any one segment of the Mozambique coastline. The impact of each storm greatly depends on the local

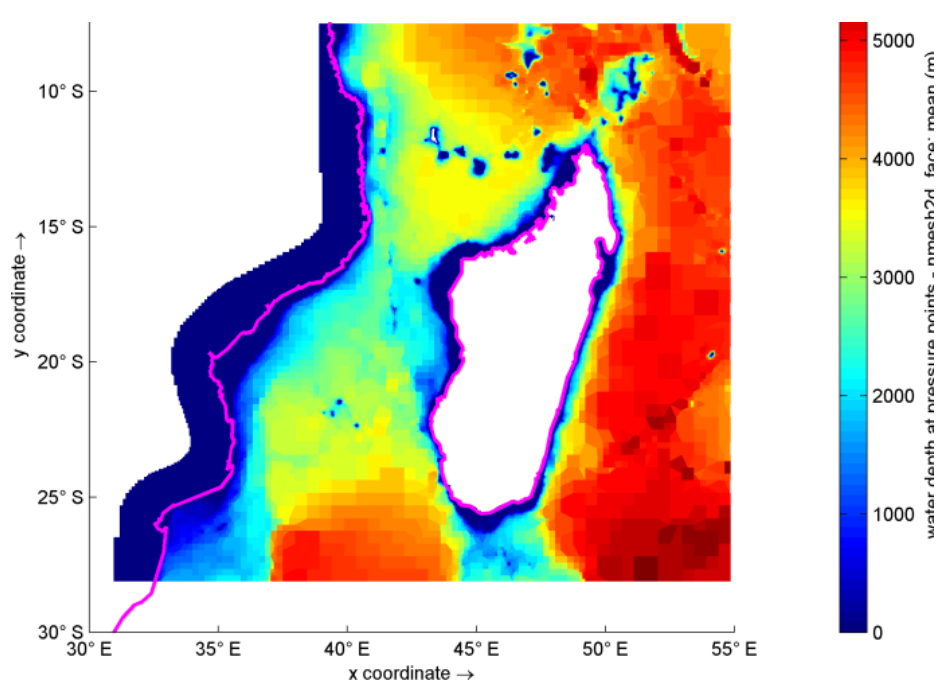

Figure 4. Bathymetry as used in computational grid. Coastline is shown in magenta. characteristics (e.g. shape and depth) of the coastline and shelf, the storm track and local vulnerabilities. In a recent study a probabilistic national-level coastal surge hazard model has been developed for Mozambique, accounting for Sea Level Rise projections for 2050 and extreme still water level. The model includes extreme tidal water levels, wave setup (from ERAinterim) and cyclone storm surge levels, wave set-up and tides.

The regional model used, was based on GTSM. For the purposes of this study, the resolution near the Mozambique coast was refined even further, to approximately 1.5 $\mathrm{km}$. The depth data of the computational grid is based on the GEBCO bathymetry, at 0.5 minute resolution. The extreme tidal water levels along the coast were obtained using FES2012 (Lyard, et al. 2006), and 
the extreme storm surge levels were obtained using GTSM for selected tropical-cyclones. These extreme water levels together with the wave set-up were used to produce the desired return values of the total water levels for Mozambique, which were subsequently used to determine the flood hazard and associated risk.

This study showed how in a relatively data poor area GTSM can be used to create a model to perform a sensible coastal surge hazard assessment study.

\subsection{GLOFFIS - operational boundary conditions for Belgrade (Serbia)}

GLOFFIS is used to run a local hydrodynamic model for a May 2014 flood event in Belgrade (Serbia). The local flood impact forecasts are calculated using Delft-FIAT. Delft-FIAT (Flood Impact Assessment Tool) is a flexible Open Source toolset for building and running flood impact models that are based on the unit-loss method. The unit loss method is a common and standard way of calculating flood impacts (De Bruijn, 2005). It is using a hazard map (usually water depth or other hazard variables), exposure data (object maps or landuse map), and for each object/land-use category the relationship between the hazard and the flood impact (e.g. vulnerability/depth-damage function). Figure 5 shows an overview of this method.

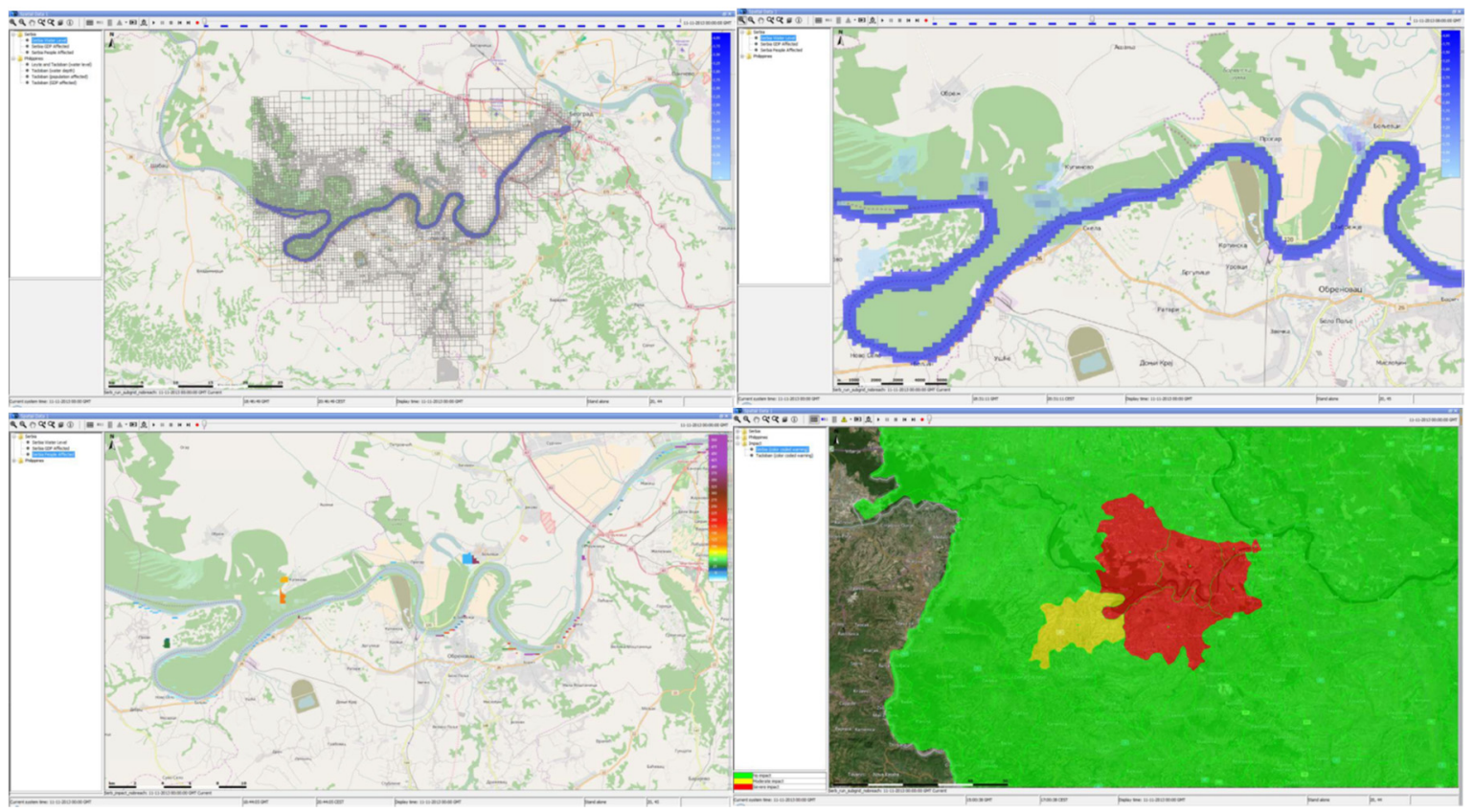

Figure 5. From top left to bottom right: Local hydrodynamic model for Sava river, Water depth, Population affected and Warning levels for the Belgrade case

\section{DATA DISSEMINATION}

\subsection{Globalfloodforcast.com}

Mid 2017, during the Global Flood Partnership meeting in Tuscaloosa (USA), Deltares launched the website http://globalfloodforecast.com. This viewer presents the results of GLOSSIS and GLOFFIS. With this freely accessible viewer, Deltares assists early warning for flood risk assessments and analyses worldwide.

The main feature is the operational global storm surge forecasts and threshold exceedances from GLOSSIS for about 16,000 coastal segments with more or less homogeneous characteristics.

From GLOFFIS it includes relative coarse scale global riverine ensemble and deterministic flood forecasts using the $0.5 \mathrm{~W} 3 \mathrm{RA}$ model and a river routing network using multiple meteorological data sources (NOAA, ECMWF). Currently, reservoirs are not yet included. Note that GRDC gauge locations not always coincide with the coarse river network. Furthermore, high resolution distributed hydrological models are included (e.g. Myanmar). Hydrological data assimilation is applied using OpenDA-wflow. Currently, this is implemented for approximately 15 gauges in Europe as part of the H2020 www.imprex.eu project. 
De Kleermaeker et al., Global operational data services for storm surge and fluvial flood forecasting

\subsection{Data service for full resolution results}

It is foreseen that the full or higher resolution results will be provided through a service with subscription fee by the end of 2017. This will include both the operational forecast data, as well as access to the archived forecasts. All forecasts that have been produced since the system went live in the fall of 2016 are stored in an archive. It is also possible to have a re-analysis performed for a specific period of interest as part of the data service.

The data service will be provided for an annual fee, with formal support and service levels to match. While these details are being worked out, the data is already made available to a limited number of beta testers.

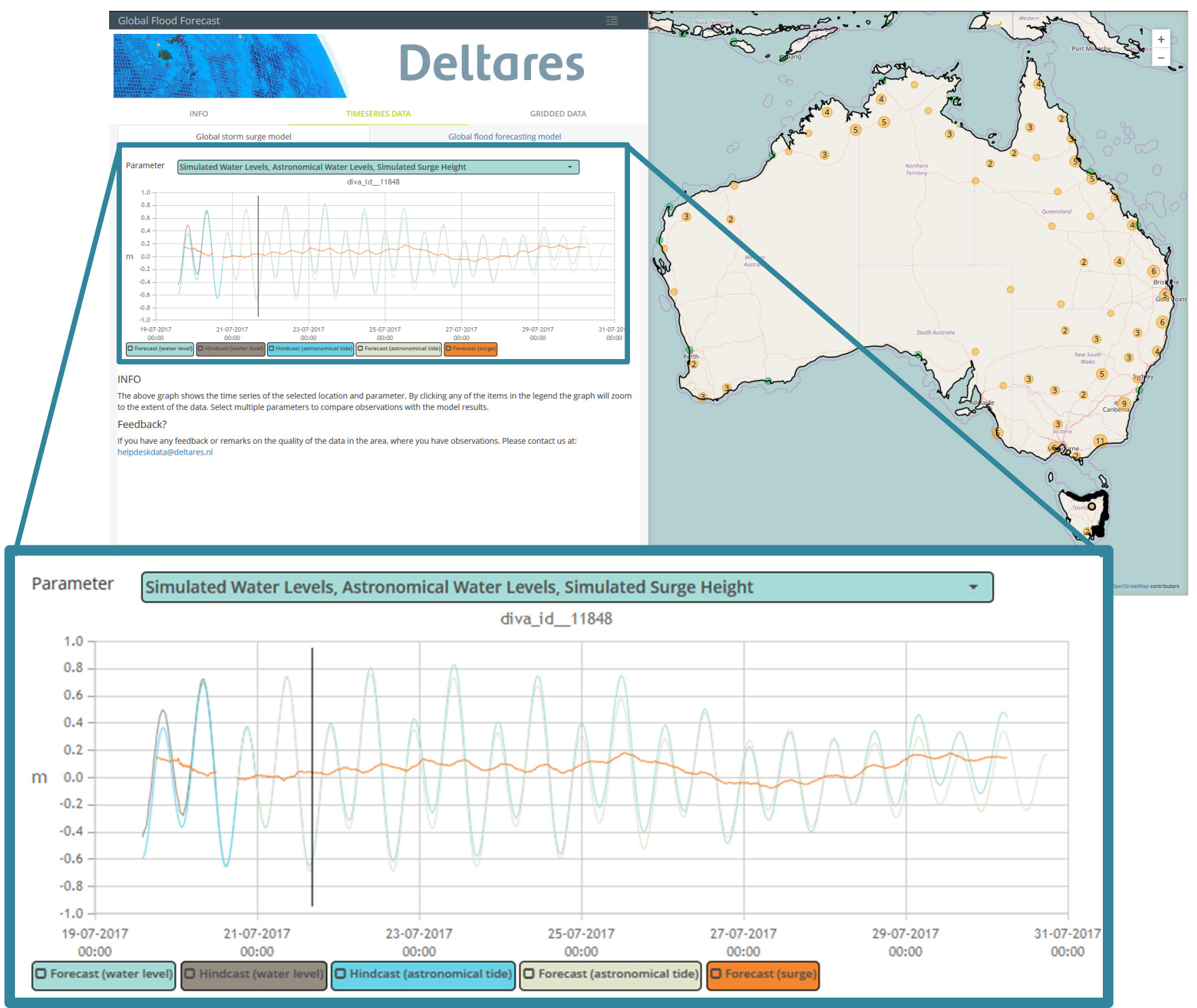

Figure 6. Screenshot of Globalfloodforecast.com, with a zoomed in view of the timeseries forecasting the combined storm surge and tide for the eastern coast of Tasmania (DIVA segment 11848)

\section{CONCLUSIONS}

GLOSSIS provides forecasts on water level and storm surge at the global scale, and can be used to provide high-quality boundary conditions for finer-scale, regional models and to study the global effects of climate change. Additionally, it can be used as a predictive tool for the risk of storm surge to coastal areas in real time, which is lacking for many communities on a global scale. Through the use of a flexible mesh GTSM has a coastal resolution of only $5 \mathrm{~km}$, not far from the resolution of many regional models, and work is 
De Kleermaeker et al., Global operational data services for storm surge and fluvial flood forecasting

ongoing to further increase the coastal resolution. With such a global tide and surge model, the concept of appropriate scale in surge modelling is rapidly being re-defined.

GLOFFIS has shown to be an excellent platform to experiment with methods to improve flood forecasting globally. The early results with CONUS show that it possible to improve the initial state estimate of global hydrological forecast models by assimilating streamflow observations and hence improve forecasted discharge.

With this operational global forecast data becoming available for all to use, it provides the opportunity for a new approach to flood and storm surge forecasting globally.

\section{REFERENCES}

Alfieri L, Burek P, Dutra E, Krzeminski B, Muraro D, Thielen J, Pappenberger F (2013). GloFAS - global ensemble streamflow forecasting and flood early warning. Hydrol Earth Syst Sci, 17:1161-1175.

Apecechea, M. I., et al. (2017). Effects of self-attraction and loading at a regional scale: a test case for the Northwest European Shelf. Ocean Dynamics 67.6: 729-749.

De Bruijn, K.M. (2005). Resilience and flood risk management. A systems approach applied to lowland rivers. PhD thesis. Delft University of Technology, Delft, The Netherlands.

Deltares (2017). iD-lab - Interactive data research laboratory addressing water-related issues worldwide, Deltares Brochure https://www.deltares.nl/app/uploads/2015/01/PB iD-Lab-web.pdf

ECMWF. TIGGE - The THORPEX Interactive Grand Global Ensemble, http://tigge.ecmwf.int/ (Accessed September 9, 2015).

Emerton, R. E., Stephens, E. M., Pappenberger, F., Pagano, T. C., Weerts, A. H., Wood, A. W., Salamon, P., Brown, J. D., Hjerdt, N., Donnelly, C., Baugh, C. A. and Cloke, H. L. (2016). Continental and global scale flood forecasting systems, WIREs Water, 3: 391-418. doi:10.1002/wat2.1137

Kernkamp, H. W. J., et al. Efficient scheme for the shallow water equations on unstructured grids with application to the Continental Shelf. Ocean Dynamics 61.8 (2011): 1175-1188.

Lyard, Florent, et al. (2006). Modelling the global ocean tides: modern insights from FES2004. Ocean Dynamics 56.5-6: 394-415.

Muis, S. et al. (2016, online). A global reanalysis of storm surges and extreme sea levels. Nature Communications 7. doi:10.1038/ncomms11969 Www.nature.com/articles/ncomms11969

Van Beek, L.P.H. and M.F.P. Bierkens (2009). The Global Hydrological Model PCR-GLOBWB: Conceptualization, Parameterization and Verification, Report Department of Physical Geography, Utrecht University, Utrecht, The Netherlands, http://vanbeek.geo.uu.nl/suppinfo/vanbeekbierkens2009.pdf

Van Dijk, A. I. J. M., Peña-Arancibia, J. L., Wood, E. F., Sheffield,J., and Beck, H. E. (2013). Global analysis of seasonal streamflow pre-dictability using an ensemble prediction system and observations from 6192 small catchments worldwide, Water Resour. Res., doi: 10.1002/wrcr.20251.

Van Dijk, A. I. J. M., G. R. Brakenridge, A. J. Kettner, H. E. Beck, T. De Groeve, and J. Schellekens (2016). River gauging at global scale using optical and passive microwave remote sensing, Water Resour. Res., 52, 6404-6418, doi:10.1002/2015WR018545.

Verlaan, M., De Kleermaeker, S., \& Buckman, L. (2015). GLOSSIS: Global storm surge forecasting and information system. In Australasian Coasts \& Ports Conference 2015: 22nd Australasian Coastal and Ocean Engineering Conference and the 15th Australasian Port and Harbour Conference (p. 229). Engineers Australia and IPENZ.

Weerts, A., Molenaar, R., Schellekens, J., Van Dijk, A. (2016). Continental scale data assimilation of discharge across CONUS: first results, 12th International Conference on Hydroinformatics, HIC 2016

Werner, A, Schellekens, J., Gijsbers, P., Van Dijk, M., Van den Akker, O., Heynert, K. (2012), The DelftFEWS flow forecasting system, Environmental Modelling \& Software, Volume 40, February 2013, Pages 65-77, https://doi.org/10.1016/j.envsoft.2012.07.010

Zijl, F., Sumihar J, and Verlaan M. (2015). Application of data assimilation for improved operational water level forecasting on the northwest European shelf and North Sea. Ocean Dynamics 65.12: 1699-1716. 